\title{
'SURGERY IN PARKINSON'S DISEASE
}

\author{
By LeSLIE C. Oliver, M.B., B.S., F.R.C.S.
}

Neurosurgeon, West End Hospital for Neurology and Neurosurgery, London; Royal Northern Hospital, London; General Hospital, Southend-on-Sea; Surgeon-in-charge, Neurosurgical Centre, Oldchurch Hospital, Romford, Essex

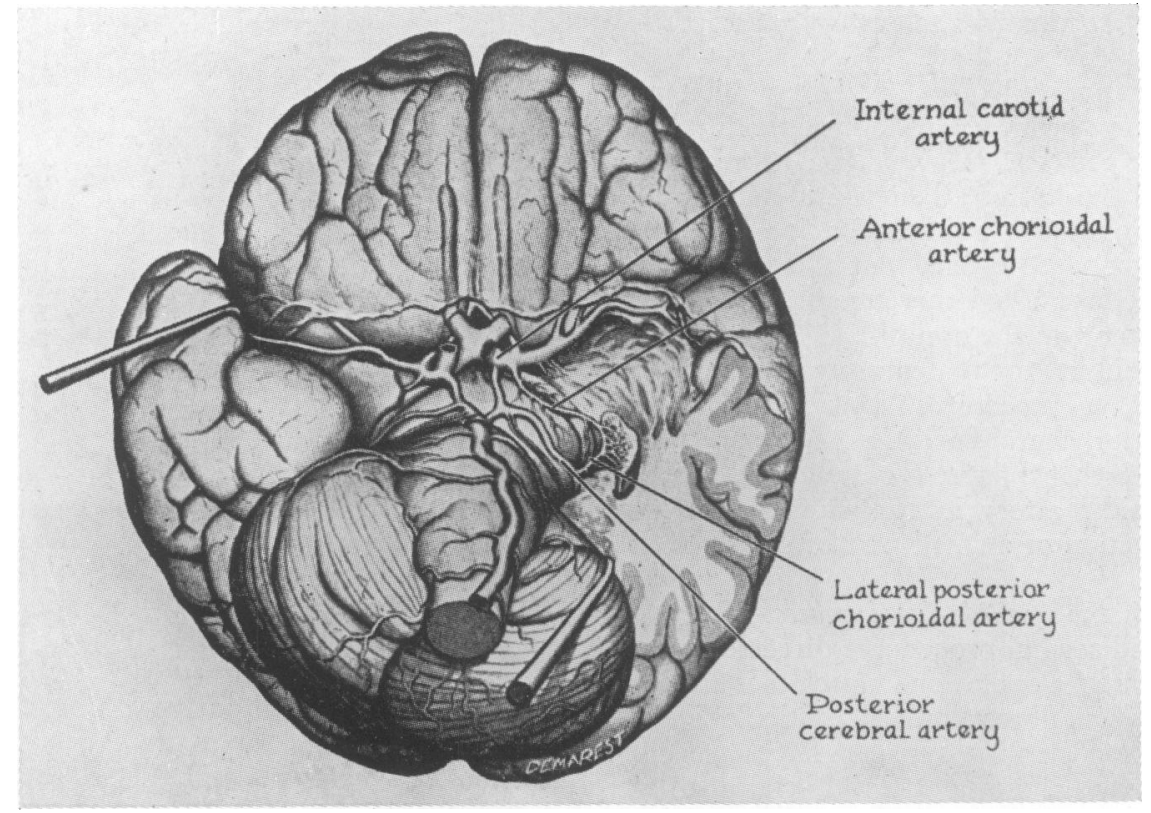

FIG. 1.-The origin and course of the anterior choroidal artery. From Carpenter, Noback and Moss.

(By courtesy of the Editor of the 'Archives of Neurology and Psychiatry.')

\section{Introduction}

All methods of surgical attack so far employed in the treatment of Parkinson's disease and postencephalitic Parkinsonism aim at symptomatic relief only. No author, however enthusiastic, has claimed to cure these diseases. Tremor, the most obvious manifestation, has claimed most attention, but although it is the commonest early symptom and is present in the majority of patients with the completely developed syndrome, it is far from being the commonest presenting symptom. To operate for tremor when disability is the complaint leads only to increased disability. By disability I mean slowness and poverty of movements despite the presence of adequate muscular power. Some patients-a small minority-seek relief from severe embarrassing or disabling tremor; it is from this group that patients are selected for operation.
In this brief report the operative procedures are arranged in anatomical rather than chronological order.

\section{Operations Directed at the Globus Pallidus}

Coagulation of the anterior choroidal artery.This operation was first performed by Cooper (I953). Occlusion of this vessel (Fig. I) causes partial infarction of the globus pallidus, one of the ganglia supposed to be in a state of degeneration in the Parkinsonian syndrome.

While attempting a pedunculotomy on a patient suffering from Parkinson's disease, Cooper accidentally damaged the anterior choroidal artery and was obliged to coagulate it. The pedunculotomy was then abandoned. After operation the patient was nevertheless found to be free from tremor on the opposite side, but there was no 
hemianopia, hemiplegia or hemianaesthesia, which are expected to follow occlusion of the anterior choroidal artery (Abbie, 1933).

Cooper has continued to coagulate the artery for Parkinson's disease. He carries out routine angiography to demonstrate the artery and any variations of its origin. It usually arises from the internal carotid artery just above the point of origin of the posterior communicating artery. The vessel is exposed by the temporal route and retraction of the temporal lobe. At least $\mathrm{I} \mathrm{cm}$. of the artery is coagulated in order to destroy anastomotic vessels.

Cooper has reported on 34 patients; bilateral operations were performed on six of them. His mortality is Io per cent. but he claims elimination of tremor and rigidity in all surviving patients.

Browder (1954) has published records of two patients on whom he carried out this operation, but the only effect noted was a reduction in the rate of the tremor on the opposite side.

Although Abbie (1933) demonstrated staining of many important structures* after injecting dye into the anterior choroidal artery, Mettler et al. (1954) showed that bilateral coagulation of the anterior choroidal artery in the chimpanzee resulted in infarction of a small part of each globus pallidus only.

Division of the pallido-fugal fibres.-Meyers (1942) has tried several procedures directed at the basal ganglia but the operation he prefers is section of the pallido-fugal fibres (the ansa lenticularis and the fasciculus lenticularis-Fig. 2). He carries out the section through the lateral wall of the third ventricle with a specially designed instrument. The third ventricle is approached through the frontal lobe and the anterior horn of the lateral ventricle. Meyers (1955) has performed. 22 operations in which section of the pallido-fugal fibres only was done, and his results are as follows:

No. of Patients

Much improved (tremor-free; some rigidity persisting; no clinical neurological deficits consequent to surgery)

8

Improved (tremor and rigidity reduced but not abolished; or if abolished, attended by some degree of post-operative dyspraxia, paresis

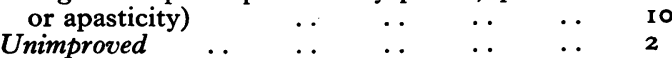

Operative Mortality .. $\quad \ldots \quad \ldots$

(Patients were followed up for a minimum of 18 months and a maximum of $13 \frac{1}{2}$ years.)

*The globus pallidus, the subthalamic nucleus, the ventrolateral nucleus of the thalamus, the substantia nigra, the red nucleus, the ansa lenticularis, the hippocampus, the optic tract, the lateral geniculate body, the posterior limb of the internal capsule and, finally, the choroid plexus of the inferior horn of the lateral ventricle.

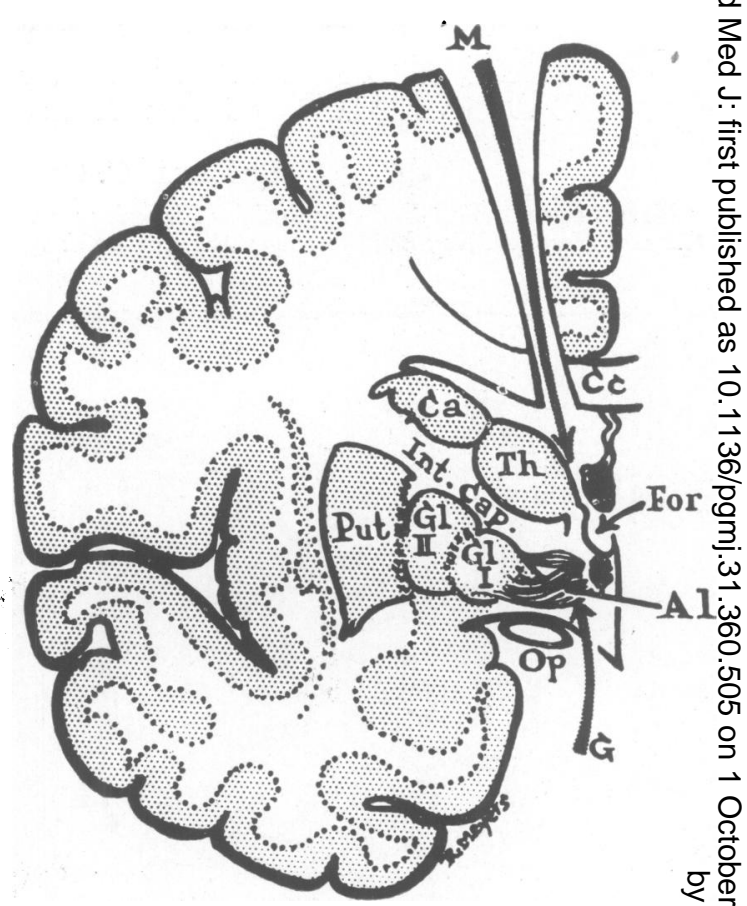

FIG. 2.-Russell Meyer's diagram showing A.I.-TRe pallido-fugal fibres; M.-Meyers' transventricudar route; G.-Guiot's approach.

Other writers claim good results following division of the pallido-fugal fibres using othero techniques (Fénelon, 1952, 1953; Guiot andô Brion, 1953; Spiegel and Wycis, 1954).

Carpenter et al. (1950) have been able to produce $\overrightarrow{0}$ choreoid movements in monkeys by partial destruction of the subthalamic nucleus and have? reduced or eliminated these movements by par-0. tially destroying the contralateral globus pallidus:을 These experiments were checked by histological methods.

Operations on the basal ganglia or their efferent. fibres are technically difficult, but have theo advantage of avoiding the pyramidal tract, although other more vital structures may be in danger. In? most cases there is no check on what has been done.

Workers in this field seem to ignore the sub-ñ stantia nigra which is involved to a greater extent than the globus pallidus in Parkinson's disease.

\section{Ablation of Cortical Projection Areas}

Excision of Area 4.--Horsley (1909) was theo first to operate on the frontal cortex for involuntaryo movements. He showed that removal of the pre? central gyrus, Area 4 of Brodmann (Fig. 3), abolished contralateral athetosis. Bucy ( 1948 ande 195 I) has also carried out excisions of the pre- 


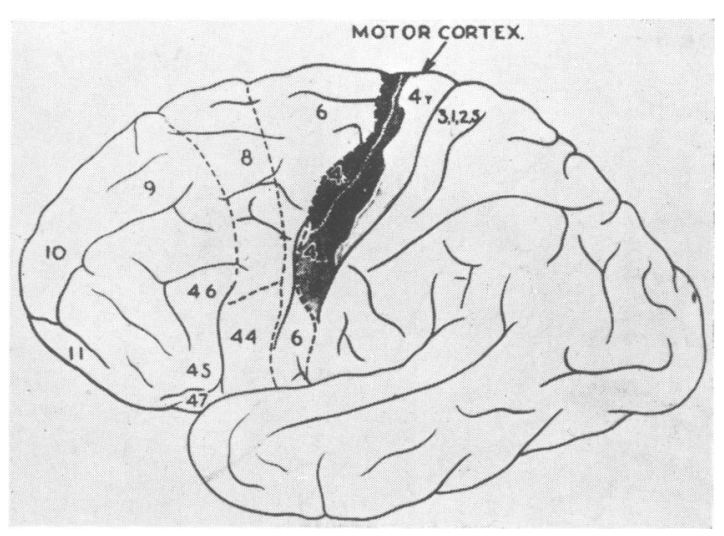

FIG. 3.-Brodmann's areas.

central cortex for choreo-athetosis and tremor of traumatic origin. He has succeeded in completely eliminating both these types of involuntary movement at the expense of spastic paralysis of the affected limbs. He excises Area 4 for tremor and both Areas 4 and 6 for choreo-athetosis. This type of operation is suitable only for violent unilateral involuntary movements when these are considered to be a worse handicap than paralysis. From these experiences Bucy concludes that involuntary movements arise in the pre-central area which is released from the control of the destroyed basal ganglia. However, the essential fact about the pathology is that the affected ganglia, with the occasional exception of the substantia nigra, are not destroyed but are in various stages of degeneration, with normal and abnormal cells lying side by side. Therefore there is abnormal function rather than absence of function.

Ward, McCulloch and Magoun (1948) have produced alternating tremor at rest in monkeys by electrocoagulation of parts of the reticular formation, and have temporarily eliminated the tremor by excision of Areas 4 and 6.

Excision of Area 6.-Klemme (1940), without publishing the details of his work, maintains that Parkinsonian tremor can be abolished contralaterally by excision of the pre-motor Area 6 of Brodmann without damage to Area 4 (Fig. 3). The patients I have seen who have been operated on by Klemme have had a severe spastic hemiplegia, and reference to one of his published diagrams and its caption (Fig. 4) will show that infarction is almost certain to occur beyond the line of excision. Even if he used the sub-pial technique of excision there remains the difficulty of defining the border between Areas 4 and 6 by electrical stimulation, for there is great variability in the threshold of the human cerebral cortex, and occasionally there is not a sufficient margin

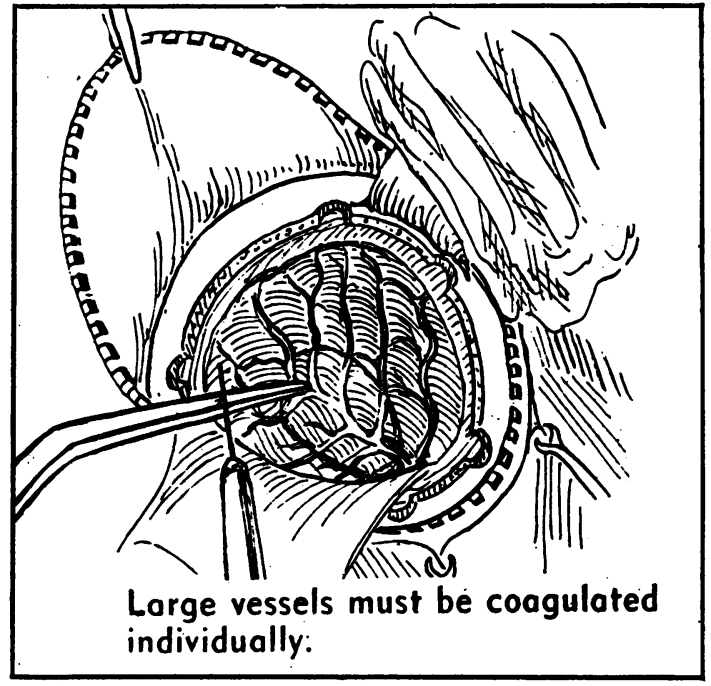

FIG. 4.-One of Klemme's diagrams reproduced with its original caption, by kind permission of the Editor of Modern Medicine.

between ineffectual and convulsive currents. Furthermore, Brodmann's Area 4 gives origin to a considerable non-pyramidal outflow which would escape destruction if, as Klemme claims, he can incise the cortex accurately between Areas 4 and 6. Other workers (Browder, 1947; Bucy, 195I; Putnam, I940; Sachs, I942; Sjöqvist, 1954) have failed to confirm Klemme's results.

\section{Operations on Cortico-Fugal Fibres}

Section of the anterior limb of the internal capsule.-This operation was first tried by Meyers (I940) and later adopted by Browder (1948) as his standard operation for the relief of unilateral tremor (Fig. 5). A small frontal flap is opened under local anaesthesia and the internal capsule is approached through the anterior horn of the lateral ventricle and exposed by removal of the head of the caudate nucleus. Division of the capsular fibres is carried out piecemeal until contralateral tremor is abolished and flexion movements of the fingers are nearly lost. There is a post-operative hemiplegia which quickly diminishes. The amplitude of the tremor is greatly reduced. The operation is recommended for patients with unilateral tremor only. Browder (1952) has reported improvement in 14 patients out of 16 . There were two deaths.

Pedunculotomy.-This operation was first performed by Walker (1949) for a case of hemiballismus (Fig. 6), and by Guiot and Pecker (1949) for Parkinsonian tremor, but the latter have given it up (Guiot, I955) because of the profound hemi- 
-Lateral view, showing site of cortical incision and approach to lateral ventricle.

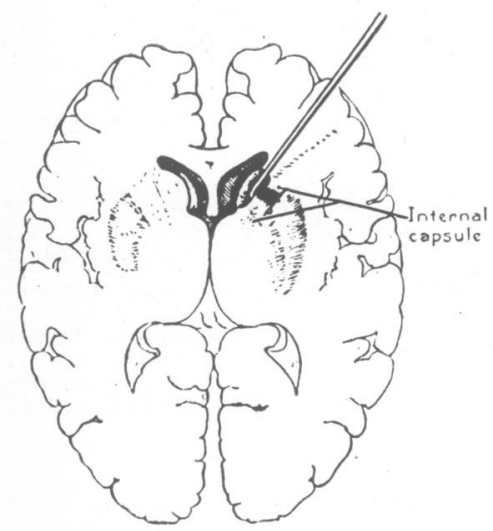

-Beginning of the section of the fibres of the anterior limb of the internal capsule.

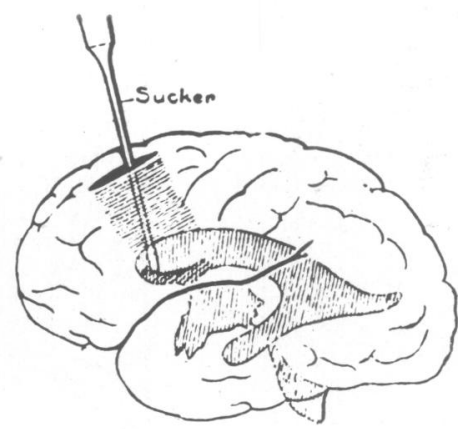

- Removal of part of the head of the caudate nucleus to expose the anterior limb of the internal capsule.

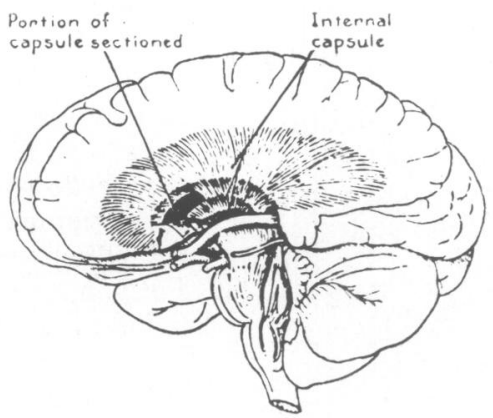

-Approximate extent of the division of the anterior limb of the internal capsule.
FIG. 5.-Dr. Jefferson Brow- $-\omega$ der's illustrations of anteriori capsulotomy reproduced by kind permission of the Editor of the American fournal of Surgery.
FIG. 6.-Reproduction of Earl Walker's illustration showing the extent of his pedunculotomy. Neurologica.')

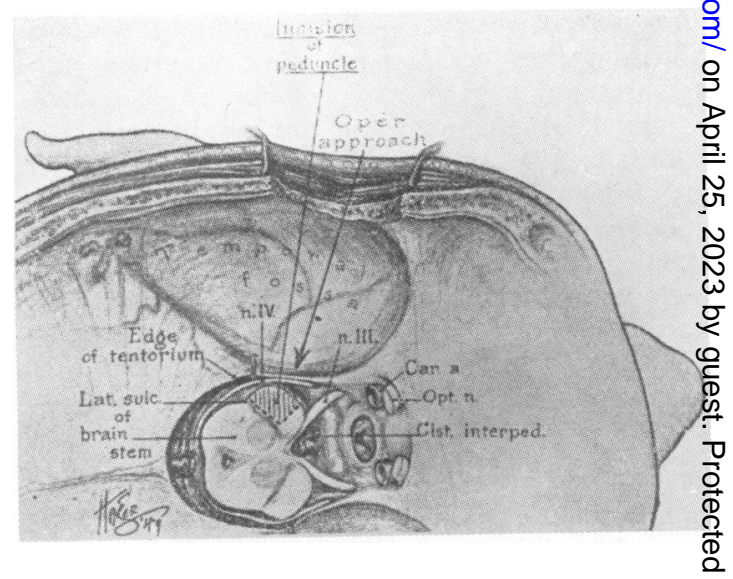




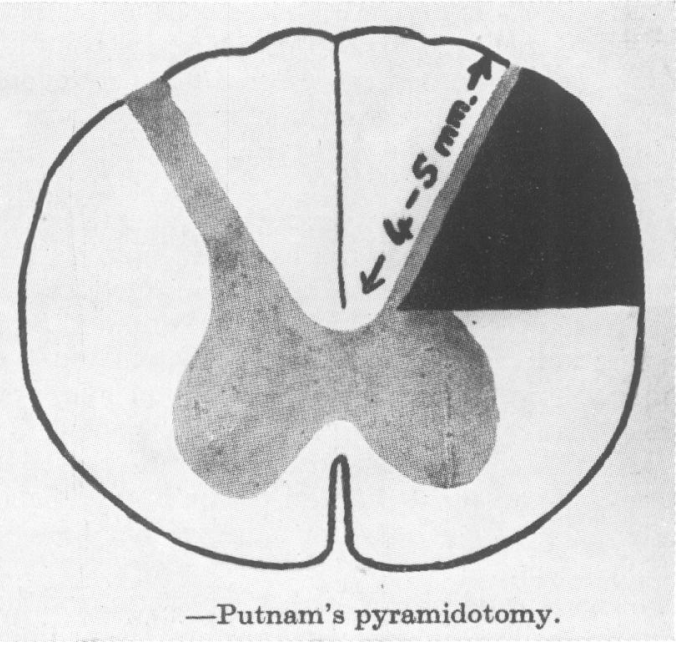

FIG. 7.

paresis that must be produced to eliminate tremor completely.

\section{Operations on the Spinal Efferents}

Pyramidotomy.-One of the patients whose record appears in James Parkinson's (1817) monograph had a cerebral apoplexy and immediately lost the tremor on the hemiplegic side. This observation, together with the knowledge that section of the pyramidal tract in monkeys causes little or tho lasting disability, led Putnam (1940, 1950) to divide the crossed pyramidal tract unilaterally at the second cervical level for unilateral tremor (Fig. 7). Out of 22 patients, 15 showed reduction of tremor. Most of these patients recovered from the post-operative hemiplegia. The minimum follow-up period was one year.

I have done 76 Putnam operations and the results are classified as follows:

(a) Unilateral cordotomy for unilateral tremor:

$\begin{array}{lllllr}\text { Operations } & \ldots & \ldots & \ldots & \ldots & 20 \\ \text { Successful } & \ldots & \ldots & \ldots & \ldots & \text { 10 } \\ \text { No change } & \ldots & \ldots & \ldots & \ldots & 9 \\ \text { Worse } & \ldots & \ldots & \ldots & \ldots & \text { I } \\ \text { Deaths } \ldots & \ldots & \ldots & \ldots & \ldots & 0\end{array}$

(b) Unilateral cordotomy for the worst side:

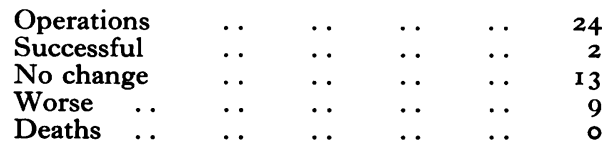

(c) Bilateral cordotomy for bilateral tremor (two stages):

\begin{tabular}{|c|c|c|c|c|}
\hline Operations & . & - & $\cdots$ & ro (5 patients) \\
\hline Successful & $\cdots$ & $\cdots$ & $\cdots$ & I (patient) \\
\hline No change & $\cdots$ & . & $\cdots$ & I \\
\hline Worse $\quad$. & $\cdots$ & $\cdots$ & $\cdots$ & I \\
\hline Deaths & .. & $\ldots$ & $\ldots$ & 2 \\
\hline
\end{tabular}

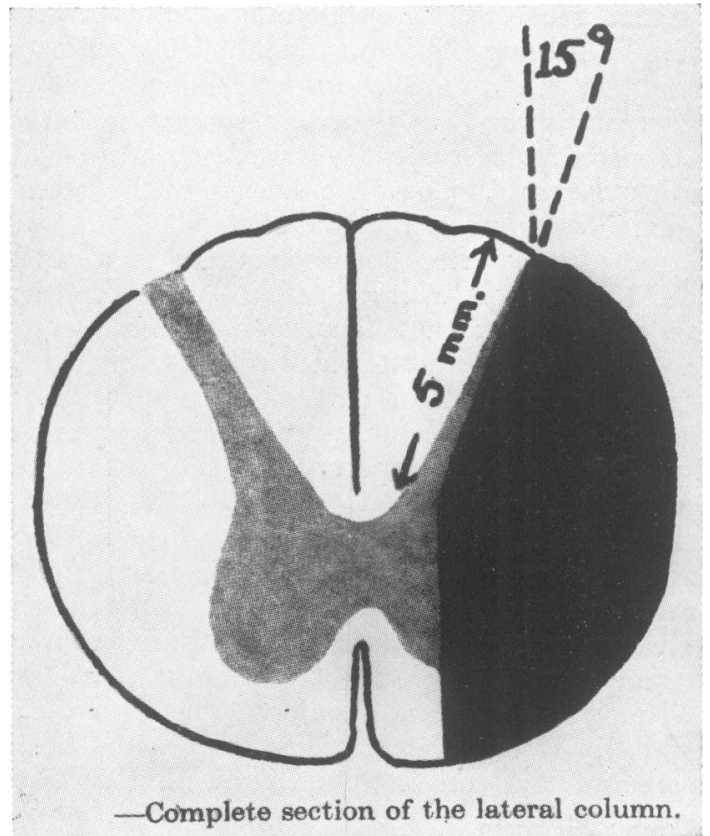

FIG. 8.

(d) Bilateral cordotomy for bilateral tremor (one stage):

$\begin{array}{lllllr}\text { Operations } & \ldots & \ldots & \ldots & \ldots & 20 \\ \text { Successful } & \ldots & \ldots & \ldots & \ldots & 3 \\ \text { No change } & \ldots & \ldots & \ldots & \ldots & 6 \\ \text { Worse } & \ldots & \ldots & \ldots & \ldots & 9 \\ \text { Deaths } \ldots & \ldots & \ldots & \ldots & \ldots & 2\end{array}$

A successful result implies that in the patient's opinion worthwhile improvement had been accomplished. Complete elimination of tremor by this operation is exceptional.

Several interesting facts were established by these cordotomies. Perhaps the most surprising of them is that little or sometimes no neurological deficit follows division of the posterior half of the lateral column at the second cervical level, even when bilateral cordotomy is performed.

Patients with bilateral manifestations of the disease have little prospect of relief by pyramidotomy, although those with unilateral tremor have a 50 per cent. chance of considerable reduction in the amplitude of the tremor. Patients who, after cordotomy, had evidence of damage to the spinothalamic tract had most relief. This last observation led me eventually to divide the whole of the lateral column.

Complete section of the lateral column.-This operation (Oliver, 1950, 1953) is performed on patients with marked longstanding unilateral tremor and no suspicion of any of the Parkinsonian manifestations in the opposite limbs (Fig. 8). 
Tremor must be the presenting symptom and must be making life intolerable, and the patients should be free from psychopathic tendencies. The operation is rarely indicated in patients with the generalized syndrome, for the disability is likely to be greatly increased. Complete division of the lateral column should never be done bilaterally.

Immediately after operation there is a total flaccid hemiplegia with a positive Babinski reflex; tremor is absent; there is analgesia and thermanaesthesia on the opposite side up to a level which usually includes all or part of the upper limb; Horner's syndrome is always present but eventually disappears. Temporary retention of urine occurs in some cases.

Recovery from the hemiplegia begins in a few days. It occurs more quickly and more completely in the lower than in the upper limb. All patients were able to walk without assistance in from three to four weeks. Rigidity, whether cog-wheel or lead-pipe in character before operation, is usually reduced. If cog-wheel rigidity is present before operation it is converted into lead-pipe rigidity by the operation.

Results:

\begin{tabular}{|c|c|c|c|c|}
\hline Operations & $\cdots$ & $\cdots$ & . & . \\
\hline Successful & .. & . & . & . \\
\hline Failures .. & $\cdots$ & $\cdots$ & $\cdots$ & $\cdots$ \\
\hline Deaths $\quad \ldots$ & .. & . & $\ldots$ & . \\
\hline
\end{tabular}

Follow-up: Longest period, six years five months; shortest period, three years six months (three more than six years; eight more than five years but less than six years).

Almost complete abolition of tremor is obtained; the hemiparesis is much less than would be expected and was severe in only one of my patients, who had an almost useless upper limb and had to have an arthrodesis of her ankle and tarsal joints.

Sjöqvist (1954), just before he died, published his experience with this operation. He reported I I successful results out of I $_{7}$ cases. One patient died from pulmonary embolism. He stated that the majority of his patients were completely incapacitated at the time of operation and seven patients were able to return to work afterwards. His conclusions regarding the indications for operating are the same as my own.

Le Beau (1955) has also had successful results with complete section of the lateral column.

Neuroanatomy.-Some conclusions regarding the anatomy of the human spinal cord seem justified by the foregoing experiences. The lateral pyramidal tract is evidently not the slender bundle represented in textbook diagrams, for the extent of residual paresis following cordotomy in the human subject increases as the section is extended forward and is greatest when the whole of the lateral column is divided. Sometimes an incision? limited to the posterior half of the lateral column, $\stackrel{\mathbb{Q}}{\varrho}$ in the cervical region, causes no permanent $c$. paresis, and spinothalamic tractotomy, performed for intractable pain, usually produces little or no? permanent paresis. It may, therefore, be con-등 cluded that the lateral pyramidal tract is diffusely distributed throughout the lateral column with a tendency for its fibres to be concentrated in the posterior part of the lateral column. Thesew observations are derived from cordotomy in the $\overrightarrow{0}$ upper cervical region. The situation may be different at lower levels.

Bilateral division of the posterior spino-cerebellaro tracts and unilateral division of the anterior and posterior spino-cerebellar tracts are without demonstrable effect.

Horner's syndrome is rare after section of the posterior half of the lateral column and after spinothalamic tractotomy, but is always present as aO temporary phenomenon after complete section of the lateral column. It follows that the nerve ${ }_{-}$ fibres concerned are diffusely distributed in the $\vec{O}$ human spinal cord.

\section{Conclusion}

I wish to stress that only a small proportion of $\vec{f} \vec{c}$ patients suffering from Parkinsonism can deri benefit from surgery, and great care is necessafy응 in their selection. Exaggerated claims for surgery have no doubt been made but it is important that $\frac{}{0}$ prejudice should not deprive some patients of symptomatic relief.

\section{Historical Note}

This year (1955) is the bicentenary year of $\stackrel{\supset}{\supset}$ James Parkinson (I755-1824) who, while working? as a general practitioner in the East End of London, wrote a short monograph on the disease 3 . which now bears his name.

\section{BIBLIOGRAPHY}

ABBIE, A. A. (1933), Brain, 56, 233.

BROWDER, J. (1947), N.Y. State F. Med., 47, 2589.

BROWDER, J. (1948), Amer. F. Surg., 75, 264.

BROWDER, J. (I952), personal communication.

BROWDER, J. (I954), . Neurosurg., I1, 578.

BUCY, P. (1948), Amer. F. Surg., 75, 257.

BUCY, P. (1951), f. Neurol. Neurosurg. Psychiat., 14, 108.

CARPENTER, M. B., WHITTIER, J. R., and METTLER, F. A.(1950), F. Comp. Neurol., 92, 293.

COOPER, I. S. (1953), Psychiatric Quarterly, 27, 317.

FÉNELON, F. (1952), Semaine des Hôpitaux de Paris, 28 (iv), 3775 .

FÉNELON, F. (1953), Rev. Neurol., 89, 580.

GUIOT, G., and PECKER, J. (1949), Semaine des Hôpitaux de Paris, 25 (iii), 2620.

GUIOT, G., and BRION, S. (1953), Rev. Neurol., 89, 578.

GUIOT, G. (1955), personal communication.

HORSLEY, V. (1909), Brit. med. F., ii, 125.

KLEMME, R. (1940), Arch. Neurol. Psychiat., 44, 926.

LE BEAU, J. (1955), personal communication. Bibliography continued on page 524 . 
ADAMS, F. D. (195I), New Eng. F. Med., 244, 590.

ALBRIGHT F., REIFENSTEIN, E. C., JUN. (I948), ' The parathyroid glands and metabolic bone disease. Selected studies,' Baltimore.

CHANIALS, cited by SCHUPBACH and WERNLY (below).

CITRON, K. M. (1954), Proc. Roy. Soc. Med., 47, 507.

COGAN,'D. G., ALBRIGHT, F., and BARTTER, F. G. (1948), Arch. Opthal., 40, 624.

CURTIS, A. C., TAYLOR, H., JUN., and GREKIN, R. H. (1947), f. invest. Derm., $9, \mathrm{I} 3 \mathrm{I}$.

DAVIDSON, C. N., DENNIS, J. M., MCNINCH, E. R., WILLSON, J. K. V., and BROWN, W. A. (1954), Radiology, 62, 203

DENT, C. E., FLYNN, F. V., and NABARRO, J. D. N. (1953), Brit. med. $\mathcal{F}$., ii, 808 .

DENT, C. E. (1954a), Proc. Roy. Soc. Med., 47, 508.

DENT, C. E., ANDERSON, J., HARPER, C., and PHILPOT, G.'R. (1954b), Lancet, ii, 720 .

DENZ, F. A. (1949), Quart. F. micr. Sci., 90, 317.

ESPERSEN, T. (1944), Nord. Med. (Hospitalstid), 22, 894.

FREIMAN,'D. G. (1948), New Eng. Ұ. Med., 239, 709.

FREYBERG, R. H., and GRANT, R. L. (1936), Arch. Intern Med., 58, 213 .

HARRELL, G. T., and FISHER, S. (1939), 7 . clin. Invest., 18, 687. HOLT, J. F., and OWENS, W. I. (r949), Radiology, 53, II.

HORTON, D., LINCOLN, H. S., and PINNER, M. (1939), A.M. Rev.'Tuberc., 39, 186.

KEECH. M. K. (1951), Proc. Roy. Soc. Med., 44, 728.

KLATSKIN, G., and GORDON, M. (1953), Amer. F. Med., I5, KLINEF.

Hopk. Hosp., 79.
LONGCOPE, W. T., and FREIMAN, D. G. (1952), Medicine, 31, I. MARKOFF, N. (195 I), Helvet. Med. Acta., 18, 389.

MOEHLIG'R. C. and STEINBACH, A. L. (1954), f Amer. med. Ass., $154,42$.

OWEN, K. T., and HENNEMAN, J. (1954), Brit. med. F., ii, I 141 . PARKER, J. G. (1950), Dis. Chest., 18, 49.

PHILLIPS, R. W (0), Dis. Chest., 18, 49 . 248 ,

PICKER, W., and CLARK, M. (1949), Amer. Э. Clin. Path., 19, ROTENBERG, L., and GUGGENHEIM, A. (1942), Dis. Chest.,

RUTISHAUSER, E., and RYWLIN, A. (1950), f. Urol. Paris, 56, 277.

SALVARSEN, H. A. (1935), Acta. Med. Scand., 86, 127.

SCADDING, J. G. (1950), Brit. med. $\mathcal{F}$., i, 745 .

SCHUPBACH, A., and WERNLY, M.'(1943), Acta. Med. Scand., II5, 401 .

SCHULMAN, L. E SCHOENRICH, E. $\mathrm{H}$, and HARVEY, A. M. (1952), Buli. Fohns Hopk. Hosp., 91, $37 \mathrm{I}$.

STECK, I. E., DEUTSCH, H., REED, C. I., and STRUCK, H. C. (1937), Ann. Intern. Med., ro, 95 I.

TEILUM, G. (1951), Acta. path. et. Microbiol., Scand., 28, 294. USTVEDT, H. J. (1939), Nord. Med., 2, 1677.

VAN CREVELD, S. (1941), Ann. Paediat., r57, r.

WALSH, F. B., and HOWARD, J. E. (r947), F. Clin. Endocrin., 7,644 .

WESTRA, S. A., and VISSA, J. F. (1949), Ned. Tid. Geneesk., 93, 18 .

ZELDENRUST, cited by VAN CREVELD (above).

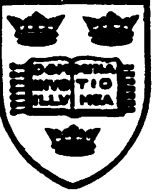

OXFORD MEDICAL PUBLICATIONS JUST PUBLISHED

\section{PERSONALITY CHANGES FOLLOWING FRONTAL LEUCOTOMY}

A CLINICAL AND EXPERIMENTAL STUDY OF THE FUNCTIONS OF THE FRONTAL LOBES IN MAN

by P. MACDONALD TOW, Ph.D., M.B., B.S., M.R.C.S.

Sometime Research Psychiatrist in the Nuffield Department of Surgery, University of Oxford; Research Physician in the Department of Clinical Research, and Assistant Physician, Runwell Hospital, Essex; Beit Memorial Fellow for Medical Research, and British Medical Association Research Scholar, University of Oxford; Clinical Research Fellow in Psychiatry at the Massachusetts General Hospital, Boston; Teaching Fellow and Milton Research Fellow at Harvard University.

With a Foreword by

SIR RUSSELL BRAIN,Bt., D.M., P.R.C.P.

278 pages

27 illustrations

35s. net

\section{OXFORDUNIVERSITY PRESS}

Bibliography continued from page $510-$ Leslie C. Oliver, M.B., B.S., F.R.C.S.

METTLER, F. A., COOPER, I., LISS, H., CARPENTER, M., - and NOBACK, C. (1954), 手. Neuropath. and Exper. Neurol.,

MEYERS, R28. (1940), Arch. Neurol. Psychiat., 44, 455.

MEYERS, R. (1942), N.Y. State F. Med., 42, 317.

MEYERS, R. (I955), personal communication

OLIVER, L. C. (1950), Lancet, i, 847 .

OLIVER, L. C. (1950), Lancet, i, 847.' Disease and its Surgical Treatment,' H. K. Lewis \& Co., Ltd., London.

PARKINSON, J. (1817), 'An Essay on the Shaking Palsy,' Sherwood, Neely and Jones, London.

PUTNAM, T. (1940), Arch. Neurol. and Psychiat., 44, 950.

PUTNAM, T., and HERZ, E. (r950), Ibid., 63, 357.

SACHS, E. (1942), Trans. Amer. Neurol. Ass., 68, 80. SACHS, E. (1942), Trans. Amer. Neurol. Ass., 68, 80.
SPIEGEL, E. A., and WYCIS, H. T. (1954), Arch. Neurol. and
Psychiat., 71, 598.

SJOQQVIST, O. (1954), Zbl. Neurochir., I4, 16.

WALKER, A. E. (1949), Acta Psychiat. kbh., $24,723$.

WARD, A. H., JUN., MCCULLOCH, W. S., and MAGOUN, H.'W. (1948), $\boldsymbol{F}$. Neurophysiology, 1 I, 3 i 7 . 